\title{
Abnormal Presynaptic Short-Term Plasticity and Information Processing in a Mouse Model of Fragile $\mathrm{X}$ Syndrome
}

\author{
Pan-Yue Deng, David Sojka, and Vitaly A. Klyachko \\ Department of Cell Biology and Physiology, Department of Biomedical Engineering, Center for Investigation of Membrane Excitability Diseases, \\ Washington University School of Medicine, St. Louis, Missouri 63110
}

\begin{abstract}
Fragile X syndrome (FXS) is the most common inherited form of intellectual disability and the leading genetic cause of autism. It is associated with the lack of fragile X mental retardation protein (FMRP), a regulator of protein synthesis in axons and dendrites. Studies on FXS have extensively focused on the postsynaptic changes underlying dysfunctions in long-term plasticity. In contrast, the presynaptic mechanisms of FXS have garnered relatively little attention and are poorly understood. Activity-dependent presynaptic processes give rise to several forms of short-term plasticity (STP), which is believed to control some of essential neural functions, including information processing, working memory, and decision making. The extent of STP defects and their contributions to the pathophysiology of FXS remain essentially unknown, however. Here we report marked presynaptic abnormalities at excitatory hippocampal synapses in Fmr1 knock-out (KO) mice leading to defects in STP and information processing. Loss of FMRP led to enhanced responses to high-frequency stimulation. Fmr1 KO mice also exhibited abnormal synaptic processing of natural stimulus trains, specifically excessive enhancement during the high-frequency spike discharges associated with hippocampal place fields. Analysis of individual STP components revealed strongly increased augmentation and reduced short-term depression attributable to loss of FMRP. These changes were associated with exaggerated calcium influx in presynaptic neurons during high-frequency stimulation, enhanced synaptic vesicle recycling, and enlarged readily-releasable and reserved vesicle pools. These data suggest that loss of FMRP causes abnormal STP and information processing, which may represent a novel mechanism contributing to cognitive impairments in FXS.
\end{abstract}

\section{Introduction}

Fragile X syndrome (FXS) is recognized as the most common inherited form of intellectual disability often associated with autism. FXS is caused by the lack of fragile X mental retardation protein (FMRP) attributable to loss-of-function mutations in the Fmr1 gene (Bassell and Warren, 2008; Pfeiffer and Huber, 2009). Despite compelling evidence for both presynaptic and postsynaptic effects of FMRP loss (Brown et al., 2001; Miyashiro et al., 2003; Liao et al., 2008; Christie et al., 2009), research on FXS has traditionally focused on dendritic abnormalities leading to defects in long-term forms of synaptic plasticity (Huber et al., 2002), as summarized in the "mGluR theory" of FXS (Bear et al., 2004). This postsynaptic theory of FXS does not, however, seem

Received Feb. 24, 2011; revised April 22, 2011; accepted June 9, 2011.

Author contributions: P.-Y.D. and V.A.K. designed research; P.-Y.D., D.S., and V.A.K. performed research; P.-Y.D. and V.A.K. contributed unpublished reagents/analytic tools; P.-Y.D. and D.S. analyzed data; P.-Y.D. and V.A.K. wrote the paper.

This work was supported in part by grants from Mallinckrodt Foundation, Whitehall Foundation, and McDonnell Foundation (all to V.A.K.). We thank Tammy Kershner and Dr. Valeria Cavalli for help with genotyping and Drs. David M. Ornitz, Maolei Xiao, and Howard Wynder for performing electron microscopy. We also thank Drs. Valeria Cavalli, Tim Holy, and Diana Owyoung for the constructive comments on this manuscript.

Correspondence should be addressed to Vitaly A. Klyachko, Department of Cell Biology and Physiology, Department of Biomedical Engineering, Washington University School of Medicine, St. Louis, M0 63110. E-mail: klyachko@wustl.edu.

DOI:10.1523/JNEUROSCI.2021-11.2011

Copyright $\odot 2011$ the authors $\quad 0270-6474 / 11 / 3110971-12 \$ 15.00 / 0$ to fully account for the marked structural and functional abnormalities observed at the presynaptic neuromuscular terminals in a Drosophila model of FXS (Zhang et al., 2001; Gatto and Broadie, 2008) or for the changes in synaptic strength and intrinsic excitability in excitatory cortical neurons of Fmr1 knock-out (KO) mice (Gibson et al., 2008). Moreover, a recent study of mosaic Fmr1 KO mice (Hanson and Madison, 2007) revealed that the reduced connectivity observed in the hippocampal circuit have a cell-autonomous presynaptic origin rather than a secondary homeostatic or trans-synaptic one. Indeed, immunoelectron microscopy localized FMRP in presynaptic terminals and axons in many brain circuits (Christie et al., 2009), and FMRP has been shown to directly interact with and modulate activity of a mostly presynaptic sodium-activated potassium channel, Slack (Brown et al., 2010). These findings suggest that regulatory functions of FMRP are not limited to controlling protein translation and indicate that at least some FXS abnormalities arise from the requirement for FMRP in presynaptic function. However, how absence of FMRP affects basic presynaptic processes, including neurotransmitter release and short-term plasticity (STP), is essentially unknown.

The potential link between FMRP loss and dysfunctions in STP is of particular interest because STP is believed to play important roles in information processing (Abbott and Regehr, 2004), working memory (Mongillo et al., 2008), and decision making (Deco et al., 2010). STP dysregulation may thus contrib- 
ute to the cognitive impairments of FXS. Previous studies that considered some of the STP components in Fmrl KO mice came to conflicting conclusions (Centonze et al., 2008; Gibson et al., 2008; Zhang et al., 2009; Olmos-Serrano et al., 2010), and no coherent picture of STP dysfunction in FXS has thus far emerged.

Here we demonstrate that loss of FMRP causes marked morphological and functional presynaptic abnormalities leading to altered STP in excitatory hippocampal synapses. Fmr1 KO mice exhibited greatly increased augmentation, presumably as a result of excessive calcium influx observed in the presynaptic neurons during spike trains, whereas faster vesicle recycling and enlarged vesicle pools led to reduced short-term depression. These presynaptic changes resulted in abnormal processing of natural stimulus trains, specifically excessive enhancement during high-frequency spike bursts associated with hippocampal place fields. These data suggest that FXS has a significant presynaptic component associated with abnormal STP and information processing that may contribute to the pathophysiology of FXS.

\section{Materials and Methods}

Animals and slice preparation. Fmr1 KO (FVB.129P2-Fmr $1^{\mathrm{tm} 1 \mathrm{Cgr}} / \mathrm{J}$; stock \#4624) and control [FVB.129P2-Pde6b ${ }^{+}$Tyr $^{c-c h} /$ AntJ; stock \#4828; hereafter referred to as wild-type (WT)] strain mice were obtained from The Jackson Laboratory. Both male and female 15- to 25-d-old mice were used. Genotyping was performed according to The Jackson Laboratory protocols. Both littermate- and age-matched controls were used and found to be indistinguishable; data for controls were thus pooled. After being deeply anesthetized with $\mathrm{CO}_{2}$, mice were decapitated and their brains were dissected out in ice-cold saline solution that contained the following (in mM): $130 \mathrm{NaCl}, 24 \mathrm{NaHCO}_{3}, 3.5 \mathrm{KCl}, 1.25 \mathrm{NaH}_{2} \mathrm{PO}_{4}, 0.5$ $\mathrm{CaCl}_{2}, 5.0 \mathrm{MgCl}_{2}$, and 10 glucose, $\mathrm{pH} 7.4$ (saturated with $95 \% \mathrm{O}_{2}$ and $5 \%$ $\left.\mathrm{CO}_{2}\right)$. Horizontal brain slices $(350 \mu \mathrm{m})$ including the hippocampus were cut using a vibrating microtome (Leica VT1200S). Slices were initially incubated in the above solution at $35^{\circ} \mathrm{C}$ for $1 \mathrm{~h}$ for recovery and then kept at room temperature $\left(\sim 23^{\circ} \mathrm{C}\right)$ until use. All animal procedures conformed to the guidelines approved by the Washington University Animal Studies Committee.

For single-synapse imaging experiments, primary cultures of hippocampal neurons were created as described previously (Kaech and Banker, 2006). Briefly, hippocampi were surgically isolated from the $\mathrm{P} 0-\mathrm{P} 1$ pups, dentate gyrus was removed, and tissue was dissociated after a brief papain treatment. Neurons were plated on astrocyte feeder layers in the Neurobasal media supplemented with B27 and held in culture for 3 weeks.

Electrophysiology. Whole-cell patch-clamp recordings using an Axopatch 200B amplifier (Molecular Devices) in current- or voltage-clamp mode were made from CA1 or CA3 pyramidal neurons visually identified with infrared video microscopy (Olympus BX50WI; Dage-MTI) and differential interference contrast optics. All the recordings were conducted at near-physiological temperature $\left(33-34^{\circ} \mathrm{C}\right)$. The recording electrodes were filled with the following (in $\mathrm{mm}$ ): $130 \mathrm{~K}$-gluconate, $0.5 \mathrm{EGTA}, 2$ $\mathrm{MgCl}_{2}, 5 \mathrm{NaCl}, 2 \mathrm{ATP}_{2} \mathrm{Na}, 0.4 \mathrm{GTPNa}$, and 10 HEPES, pH 7.3. The extracellular solution contained the following (in $\mathrm{mm}$ ): $130 \mathrm{NaCl}, 24$ $\mathrm{NaHCO}_{3}, 3.5 \mathrm{KCl}, 1.25 \mathrm{NaH}_{2} \mathrm{PO}_{4}, 2 \mathrm{CaCl}_{2}, 1 \mathrm{MgCl}_{2}$, and 10 glucose, $\mathrm{pH}$ 7.4 (saturated with $95 \% \mathrm{O}_{2}$ and $5 \% \mathrm{CO}_{2}$ ). In all experiments, NMDA receptors were blocked with AP-5 $(50 \mu \mathrm{M})$ to prevent long-term effects. For some experiments, $\mathrm{Ca}^{2+}$ currents were recorded with intracellular solution containing the following: $100 \mathrm{~mm}$ Cs-gluconate, $5 \mathrm{~mm} \mathrm{NaCl}$, $2 \mathrm{~mm} \mathrm{MgCl}_{2}, 20 \mathrm{~mm}$ tetraethylammonium (TEA)-Cl, 0.5 mм EGTA, 10 mM HEPES, $20 \mathrm{~mm}$ phosphocreatine, $50 \mathrm{U} / \mathrm{ml}$ phosphocreatine kinase, 2 mм MgATP, $0.1 \mathrm{~mm} \mathrm{NaGTP,} \mathrm{and} 0.1 \mathrm{~mm}$ leupeptin, $\mathrm{pH}$ 7.3. In these experiments, the extracellular solution was supplemented with $20 \mathrm{~mm}$ TEA-Cl and $3 \mathrm{~mm} 4-\mathrm{AP}$ (replacing equivalent amounts of $\mathrm{NaCl}$ ) and 1 $\mu \mathrm{M}$ TTX. EPSCs were recorded from CA1 pyramidal neurons (held at $-65 \mathrm{mV}$ ) by stimulating Schaffer collaterals with a bipolar electrode. For action potential (AP)-clamp recordings in CA3 pyramidal neurons, APs were first evoked by current injections in a desired temporal pattern (with the resting potential set at $-60 \mathrm{mV}$ to avoid spontaneous AP firing); these AP waveforms were then used as voltage command patterns in the same neurons. For AP-clamp experiments, cell capacitance was compensated. Series resistance compensation was enabled with $\sim 90 \%$ correction and $10-20 \mu \mathrm{s}$ lag.

Data were filtered at $2 \mathrm{kHz}$, digitized at $20 \mathrm{kHz}$, acquired using custom software written in LabView, and analyzed using programs written in MATLAB or MiniAnalysis. EPCSs during the stimulus trains were normalized to an average of five low-frequency $(0.2 \mathrm{~Hz})$ control stimuli preceding each train, to give relative changes in synaptic strength. Each stimulus train was presented four to six times in each cell, and each presentation was separated by $\sim 2$ min of low-frequency $(0.2-0.1 \mathrm{~Hz})$ control stimuli to allow complete EPSC recovery to the baseline. To correct for the overlap of EPSCs at short interspike intervals (ISIs), a normalized template of EPSC waveform was created for each stimulus presentation by averaging all EPSCs within a given train that were separated by at least $100 \mathrm{~ms}$ from their neighbors and normalized to their peak values. Every EPSC in the train then was approximated by a template waveform scaled to the peak of the current EPSC, and its contribution to synaptic response was digitally subtracted. The natural stimulus trains used in this study represent the firing patterns recorded in vivo from the hippocampal place cells of awake, freely moving rats [generously provided by Fenton and Muller (1998)]. Spikes with the ISIs $<10$ ms were treated as a single stimulus, because the delay between the action potential firing and the peak of postsynaptic currents/potentials prevented resolution of individual synaptic responses at shorter ISIs. Such treatment does not significantly affect synaptic responses to natural stimulus trains as we have shown previously (Klyachko and Stevens, 2006b). Note that, in our experimental conditions, receptor desensitization and saturation are insignificant and voltage-clamp errors are also small and do not provide a significant source of nonlinearity (Wesseling and Lo, 2002; Klyachko and Stevens, 2006a). Therefore, postsynaptic responses can be used as a linear readout of transmitter release in the relevant frequency range.

Transmission electron microscopy. Four- to five-week-old mice were used for transmission electron microscopy analysis. Mice were anesthetized with sodium pentobarbital and perfused with PBS, $\mathrm{pH}$ 7.4, followed by $2 \%$ paraformaldehyde and $2 \%$ glutaraldehyde in $0.1 \mathrm{M}$ phosphate buffer, $\mathrm{pH}$ 7.4. The brains were removed, and horizontal sections were cut at $500 \mu \mathrm{m}$ with a vibratome in $0.1 \mathrm{M}$ PBS. The hippocampal CA1 region was dissected from appropriate sections, postfixed for $1 \mathrm{~h}$ with $1 \%$ osmium tetroxide in $100 \mathrm{~mm}$ cacodylate buffer, $\mathrm{pH}$ 7.4, dehydrated using a series of ethanol dilutions, rinsed in propylene oxide, and embedded in Epon 812. Ultrathin sections $(60-80 \mathrm{~nm})$ were cut and stained with uranyl acetate and lead citrate. Complete profiles of nonperforated asymmetric synapses on dendritic spines in the stratum radiatum of CA1 were selected and photographed using a digital camera in a Hitachi 7500 electron microscope operated at $80 \mathrm{kV}$ at a final magnification of 20,000 or 80,000 . A total area of $5350 \mu \mathrm{m}^{2}$ from WT and $5671 \mu \mathrm{m}^{2}$ from KO mice were counted for quantification of synapse density. A total of 132 asymmetric synapses from three WT and 148 synapses from four KO mice were analyzed. The counts of small synaptic vesicles were separated into two groups defined according to criteria developed by Dickinson-Nelson and Reese (1983) as "docked" vesicles (located within $50 \mathrm{~nm}$ of the presynaptic active zone) and "reserved" vesicles (located 50-550 nm from the presynaptic active zone). Vesicle counts were normalized to the length of the active zone as determined by the length of postsynaptic density (Pozzo-Miller et al., 1999; Bamji et al., 2003).

Fluorescence imaging. Day 14-18 cultured hippocampal neurons were mounted on an inverted Olympus microscope (Olympus IX70) equipped with $60 \times, 1.4 \mathrm{NA}$ oil-immersion objective. Fluorescence was excited with a xenon lamp via a filter cube containing 480/40 nm excitation filter, $515 \mathrm{~nm}$ dichroic mirror, and 575/60 nm emission filter. Fluorescent signal was captured using a cooled EM CCD Hamamatsu camera and Simple PCI software (Hamamatsu). Neurons were stimulated using a pair of electrodes positioned $\sim 1 \mathrm{~cm}$ apart in the bath and controlled by the computer software via Master- 8 stimulus generator (A.M.P.I.). Only one cycle of dye staining and destaining was performed for each coverslip. Each episode of activity-evoked dye destaining was 
preceded by a set of 10 control measurements at $0.5 \mathrm{~Hz}$ in the absence of stimulation. All recordings were performed at $37^{\circ} \mathrm{C}$ using a wholemicroscope incubator equipped with a rapid feedback temperature controller (In Vivo Scientific). Image analysis was performed in NIH ImageJ (Wayne S. Rasband, NIH, Bethesda, MD; http://rsb.info.nih.gov/ij) and MATLAB. The background in recorded images was subtracted using the rolling-ball algorithm (Sternberg, 1983). The rigid-body transformation was used to align the images (Thévenaz et al., 1998), and Kalman filter was used to improve ROI selection. Dye bleaching was determined and compensated for based on the monoexponential fits to the fluorescence decay in the dendritic regions not containing ROIs. Circular ROIs of the same diameter covering the entire synapse were drawn manually in the first frame of each movie and then propagated through the entire image stack using Time Series Analyzer ImageJ plug-in (J. Balaji, Cornell University, Ithaca, NY). The activity-evoked dye destaining was determined as the difference between the ROI fluorescence intensity in a given frame and the intensity of the ROI in the last frame, normalized to the control fluorescence intensity, which was calculated for each synapse as an average ROI intensity in the first 10 frames of each movie before the stimulation onset. The stimulus protocol of $1000 \mathrm{AP}$ at $10 \mathrm{~Hz}$ was chosen because it has been shown previously to release all recycling vesicles. Based on previous estimates (Ryan and Smith, 1995), ROIs in which the overall decrease in fluorescence intensity was below $25 \%$ were unlikely to represent active synapses, and these ROIs were excluded from analysis. The kinetics of vesicle turnover was assessed as described previously (Ryan and Smith, 1995) based on the dye destaining time constant determined from the monoexponential fits in MATLAB.

Statistics. Data are presented as mean \pm SEM. Student's paired or unpaired $t$ test or ANOVA were used for statistical analysis as appropriate; $p$ values are reported throughout the text, and significance was set as $p<0.05$.

\section{Results}

\section{Altered STP in excitatory hippocampal synapses of Fmr1 KO mice}

The major changes in the levels of many presynaptic proteins involved in excitability, neurotransmitter release, vesicle recycling, and calcium homeostasis that are observed in Fmrl KO mice (Liao et al., 2008; Akins et al., 2009) suggest that various forms of STP may be affected by FMRP loss. To examine the effects of FMRP loss on STP and synaptic information processing, we used CA3-CA1 hippocampal synapses as a model system. The hippocampal circuit is a well-characterized model system to study synaptic and circuit mechanisms and for these reasons is widely used in FXS research (Braun and Segal, 2000; Huber et al., 2002; Hanson and Madison, 2007; Pfeiffer and Huber, 2007; Zhang et al., 2009; Zhang and Alger, 2010; Gross et al., 2011). From the circuit perspective, because CA3 pyramidal cells (PCs) are presynaptic to CA1 pyramidal cells, to simplify the description of changes at the CA3-CA1 synapse, below we will refer to the processes that occur in CA3 neurons as "presynaptic."

We first assessed overall changes in STP attributable to loss of FMRP by comparing synaptic dynamics during high-frequency stimulus trains in Fmrl KO mice and WT controls. EPSCs were recorded from hippocampal CA1 PCs in response to the constant-frequency stimulation of Schaffer collaterals at $2-100 \mathrm{~Hz}$ (Fig. 1). Whole-cell patch-clamp recordings were performed at near-physiological temperatures $\left(33-34^{\circ} \mathrm{C}\right.$ ) (Klyachko and Stevens, 2006a) and with intact inhibitory circuits. EPCSs during the stimulus train were normalized to an average of five lowfrequency controls preceding each train, thus representing relative changes in synaptic strength (also referred to as synaptic gain). We found that synaptic dynamics was markedly altered in the Fmrl KO mice that exhibited excessive synaptic enhancement particularly at frequencies of and above $20 \mathrm{~Hz}$ (Fig. $1 B-D$ ). The peak gain reached $4.98 \pm 0.37$-fold increase at $100 \mathrm{~Hz}$ in Fmr 1
$\mathrm{KO}$ mice versus $3.21 \pm 0.40$-fold increase in controls $(p<0.001$, $t$ test). The average gain during the trains was also significantly larger in KO than WT mice for stimulus trains at and above $20 \mathrm{~Hz}$ (Fig. 1D). These results demonstrate that FMRP loss enhances synaptic response to high-frequency stimulation.

\section{Abnormal processing of natural stimulus patterns in Fmr1 KO mice}

The marked changes in STP we observed during constant-frequency stimulation in Fmrl KO mice may have a significant impact on the synaptic information processing and may thus contribute to the cognitive impairment in FXS. To examine this possibility, we recorded EPSCs from CA1 PCs evoked by the natural spike pattern recorded in vivo from hippocampal place cells in exploring rodents (provided by Drs. A. Fenton and R. Muller, State University of New York, Brooklyn, NY) (Fenton and Muller, 1998). Place cells are known to encode information about the animal's position via high-frequency spike discharges at certain places in the environment, known as place fields (O'Keefe and Dostrovsky, 1971). Here, we used a long segment of such natural spike pattern, consisting of 256 spikes with a mean burst frequency of $26.0 \pm 1.8 \mathrm{~Hz}$ and duration of $12.9 \pm 2.2$ spikes (Fig. $2 A$, top trace).

Our previous studies have shown that STP in excitatory CA3CA1 synapses acts as a high-pass filter that selectively amplifies synaptic strength during high-frequency spike bursts associated with place fields (Klyachko and Stevens, 2006a,b). We observed the same response pattern both in WT and Fmrl KO mice (Fig. $2 A$ ), in which excitatory synaptic strength alternates between a basal near-constant value during low-frequency stimulation and another elevated near-constant value during the discharges. As during constant-frequency stimulation, however, the responses to the natural stimulus trains were markedly enhanced in the Fmr1 KO neurons selectively during the spike discharges (Fig. $2 A, B)$ (the average gain during the discharge in WT was $2.13 \pm$ $0.06, n=11$; in KO $2.60 \pm 0.10, n=13 ; p<0.001)$. This excessive enhancement in the Fmrl KO mice is more apparent when synaptic gain is plotted as a function of instantaneous stimulus frequency, i.e., the reciprocal of the interspike interval (Fig. 2C). These data were fitted with the sigmoidal Boltzmann equation, giving a significantly larger elevated gain value during the discharges in the $\mathrm{KO}$ mice (WT, $2.55 \pm 0.02$; KO, $3.29 \pm 0.04 ; p<$ 0.01 ). The transition frequencies between the gain levels were not significantly different (WT, $7.30 \pm 0.30 \mathrm{~Hz} ; \mathrm{KO}, 7.65 \pm 0.37 \mathrm{~Hz}$; $p>0.5$ ) and are similar to previously reported ones (Klyachko and Stevens, 2006b). The frequency dependence of excessive synaptic gain in Fmrl KO mice during natural stimulus trains (Fig. 2E) was similar to that during constant-frequency stimulation (Fig. $1 D$ ). Together, these results indicate that excitatory hippocampal synapses in Fmr1 KO mice exhibit hypersensitive responses to natural stimulus trains and specifically to high-frequency spike bursts associated with hippocampal place fields.

Because we recorded EPSCs in the presence of intact inhibitory circuits in the above experiments, the enhanced responses could result from possible alterations of GABAergic transmission in Fmrl KO mice (Centonze et al., 2008; Olmos-Serrano et al., 2010). To investigate this possibility, we performed the same recordings as those described above using a constant $60 \mathrm{~Hz}$ stimulus train (Fig. 3A) or a natural spike pattern (Fig. $3 B-F$ ) in the presence of the $\mathrm{GABA}_{\mathrm{A}}$ receptor $\left(\mathrm{GABA}_{\mathrm{A}} \mathrm{R}\right)$ blocker gabazine $(5 \mu \mathrm{M})$ and the $\mathrm{GABA}_{\mathrm{B}} \mathrm{R}$ blocker CGP55845 [(2S)-3-[(1S)-1-(3,4-dichlorophenyl)ethyl]amino-2-hydroxypropyl)(phenylmethyl)phosphinic acid] (2 $\mu \mathrm{M})$. The excessive increase in synaptic strength observed in Fmrl KO 
mice remained unaltered when inhibitory transmission was blocked (average gain during the discharge: WT, $1.96 \pm 0.03, n=$ $7 ; \mathrm{KO}, 2.44 \pm 0.05, n=11 ; p<0.001, t$ test $)$, indicating that the observed enhancement of excitatory responses is not attributable to alterations of GABAergic transmission in the KO mice. These data confirm that loss of FMRP causes abnormal STP in excitatory hippocampal synapses during both constant frequency and natural stimulus trains.

\section{Enhanced augmentation, but not facilitation, in excitatory synapses of Fmr1 KO mice}

The rapid synaptic dynamics during stimulus trains has been shown to result from the interplay of several presynaptic forms of STP (Zucker and Regehr, 2002). The excessive increase in synaptic strength during constant-frequency and natural stimulus trains we observed in Fmrl KO mice can arise from the increase in shortterm facilitation/augmentation, decrease in short-term depression, or a combination of both. To distinguish these possibilities, we used our previously developed approach to separate contributions of different STP components to synaptic dynamics (Klyachko and Stevens, 2006a) and to assess changes in individual components attributable to FMRP loss. Paired-pulse protocol was used first to examine changes in facilitation. Although we found a tendency toward increased paired-pulse ratio (PPR) at short interspike intervals (7-40 ms) in Fmrl KO mice, the overall differences in the pairedpulse facilitation were not significant between WT and KO mice (Fig. 4A, B), consistent with the previous report in the hippocampus (Zhang et al., 2009).

Augmentation represents a longerlasting component of short-term enhancement than facilitation (Zucker and Regehr, 2002). It operates on a timescale of several seconds and has been shown to serve as a major component of STP that sustains synaptic strength during high-frequency spike discharges (Kalkstein and Magleby, 2004; Kandaswamy et al., 2010). We examined contribution of augmentation using our previously developed protocol (Klyachko and Stevens, 2006a) and found a marked increase in augmentation amplitude in Fmr1 KO mice, particularly at frequencies of $20 \mathrm{~Hz}$ and above (Fig. 5A-D) (extrapolated augmentation for $80 \mathrm{~Hz}$ stimulus train: WT, $2.70 \pm 0.2$; $\mathrm{KO}, 4.63 \pm 0.46 ; n=8$ for each; $p<0.01$ ) (Fig. $5 B, C$ ), without significant changes in the decay time constant (WT, $6.08 \pm$ $0.83 \mathrm{~s} ; \mathrm{KO}, 4.76 \pm 0.47 \mathrm{~s} ; n=8$ for each; $p=0.32$ ) (Fig. $5 C$ ). The frequency-dependent increase in augmentation in Fmr1 $\mathrm{KO}$ mice (Fig. 5D) closely paralleled that of overall synaptic enhancement during high-frequency trains (Figs. 1D, 2C), suggesting that changes in augmentation may be one of the main contributors to abnormal synaptic dynamics in Fmr1 KO mice.
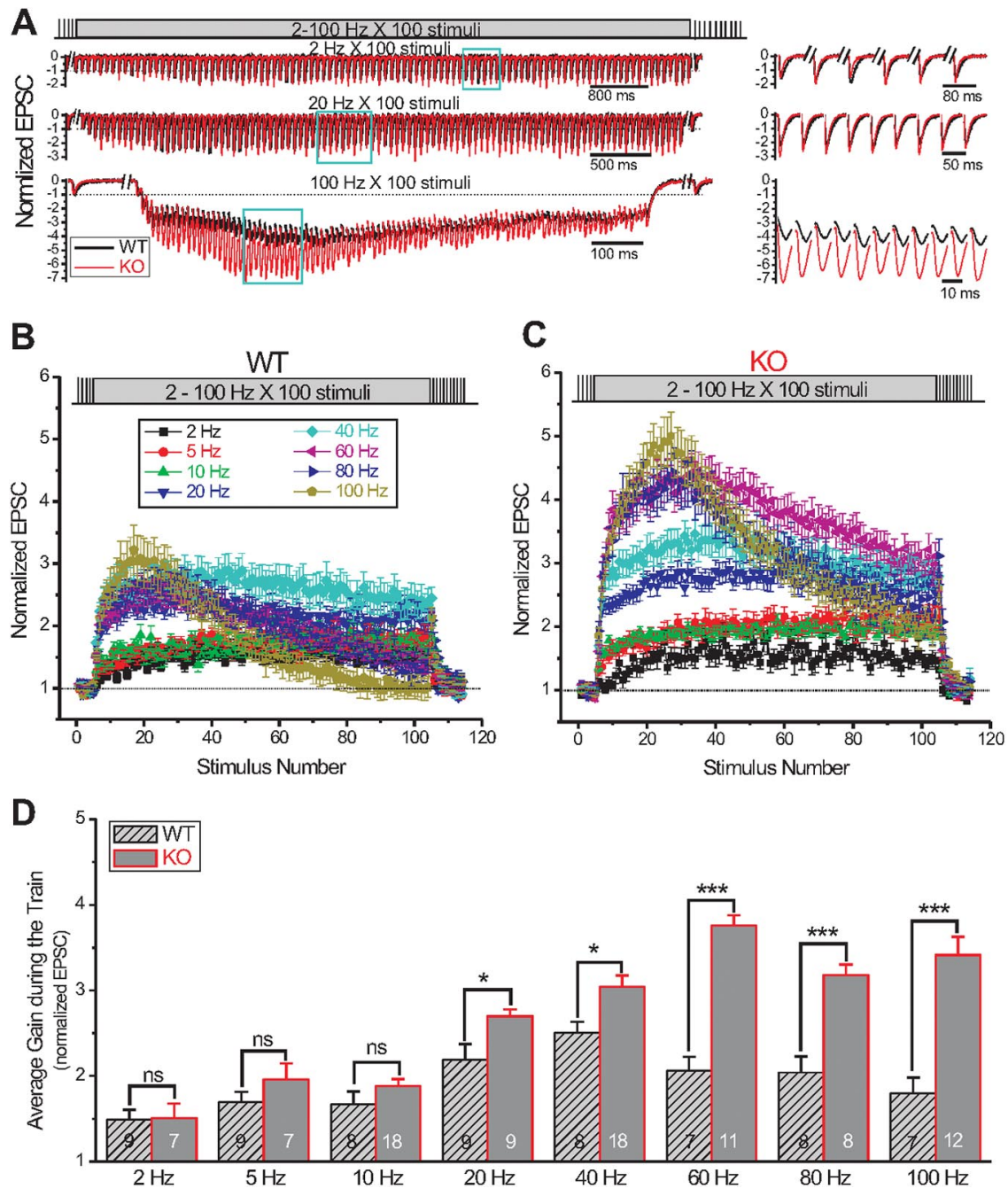

Figure 1. Altered STP in excitatory hippocampal synapses of Fmr $1 \mathrm{KO}$ mice. $A$, EPSCS were recorded from CA1 pyramidal neurons response to 100-stimuli trains at different frequencies. Examples of synaptic responses during the 100 stimuli at 2, 20, and 100 ice, recorded as described in $A . n=7-9$ for WT and $n=7-18$ for K0.D, Average synaptic gain during stimulus trains for the data in $\boldsymbol{B}$ and $\boldsymbol{C}$. The numbers of neurons tested are shown for each frequency. ${ }^{*} p<0.05,{ }^{* * *} p<0.001$; ns, not significantly different (here and in subsequent figures).

Increased calcium influx during high-frequency stimulation in Fmr1 KO mice

What are the mechanisms of these changes? Augmentation is commonly believed to arise from elevation in residual presynaptic calcium levels during repetitive activity (Zucker and Regehr, 2002). Presynaptic calcium levels are controlled by several mechanisms that include calcium influx, release and uptake from internal stores, and calcium buffering/clearance processes. The absence of significant changes in facilitation/augmentation decay kinetics suggests that calcium clearance is not likely to be significantly affected by the loss of FMRP (Zucker and Regehr, 2002), whereas release/uptake by internal stores has been shown not to play a significant role in STP in the CA3-CA1 synapse on the timescales relevant to the current study (Carter et al., 2002). Thus, augmentation may be enhanced in the absence of FMRP if presynaptic calcium influx is increased to a larger extent during high-frequency stimulation in Fmr1 KO mice than in WT mice. 

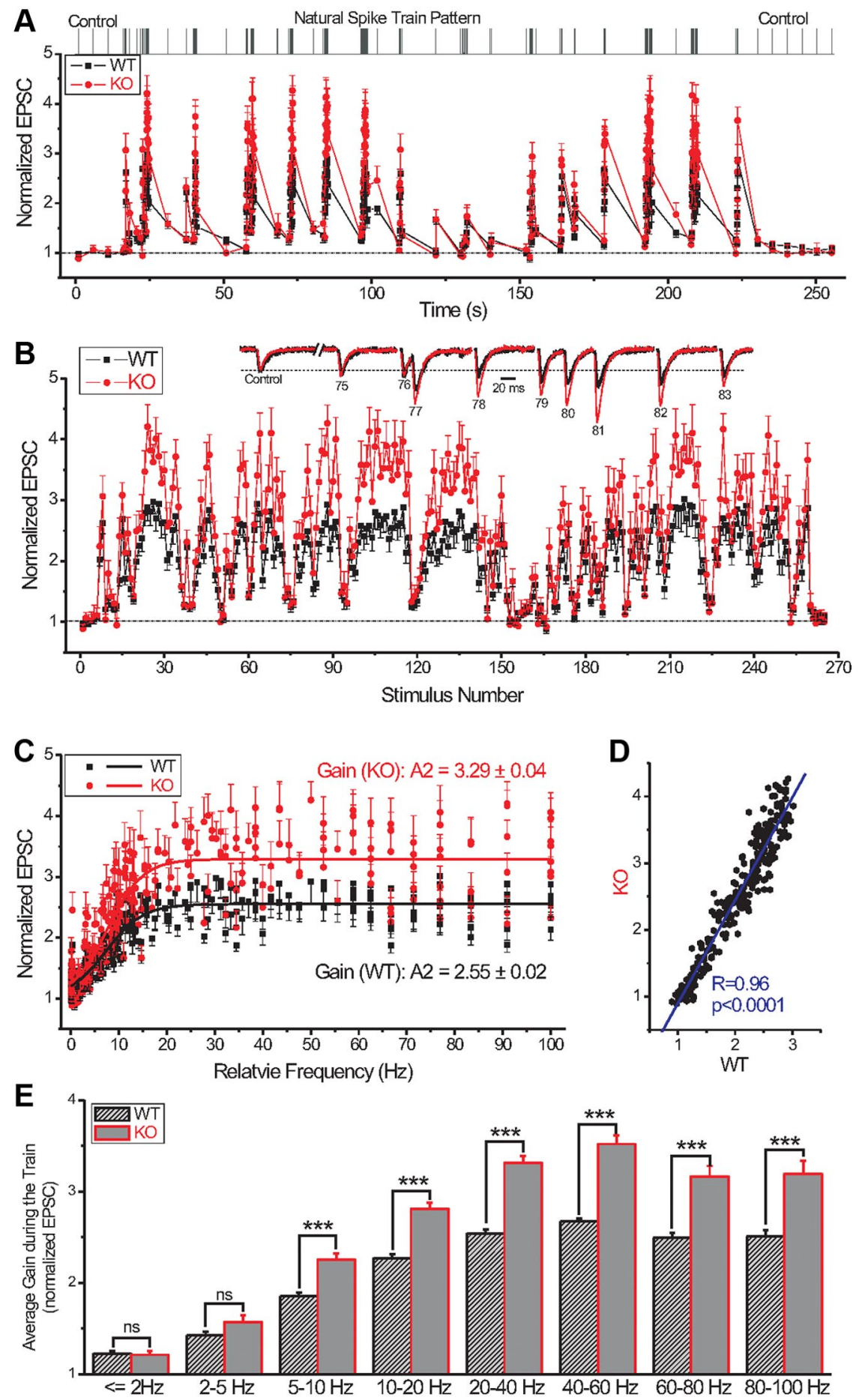

Figure 2. Abnormal processing of natural stimulus patterns in Fmr1 K0 mice. A, Changes in synaptic strength during natural stimulus trains plotted as a function of time for WT and $F m r 1 \mathrm{KO}$ mice. Note the excessive increases in synaptic strength during bursts in the Fmr $1 \mathrm{KO}$ mice. The top shows the natural stimulus pattern used (Fenton and Muller, 1998), preceded by four and followed by six control stimuli at $0.2 \mathrm{~Hz} . n=11$ and 13 for WT and $F m r 1 \mathrm{KO}$, respectively. $\boldsymbol{B}$, Same as in $\boldsymbol{A}$ but plotted as a function of stimulus number. Inset shows EPSCs 75-83 during the natural stimulus trains, scaled to their own controls for comparison. $C$, Synaptic strength during natural stimulus trains (data from $A$ ) plotted as a function of instantaneous stimulus frequency, i.e., reciprocal of interspike intervals. Solid lines represent fits to a Boltzmann equation: $y=(A 1-A 2) /\left(1+\exp \left(\left(x-x_{0}\right) / d x\right)\right)+A 2$, where $\mathrm{A} 1$ is the basal gain level, $\mathrm{A} 2$ is the elevated gain level, and $x_{0}$ is the transition frequency. $\mathbf{D}$, Normalized EPSC amplitudes during the natural spike trains in WT and KO animals are plotted point by point against each other; the correlation coefficient is determined by linear regression (blue line). Correlation analysis shows that FMRP loss alters the amplitude but not the pattern of changes in synaptic strength during natural stimulus trains. $E$, Average synaptic gain during natural stimulus trains plotted as a function of frequency bands. The frequency dependence of abnormal synaptic enhancement in $F m r 1 \mathrm{KO}$ is similar to that seen in Figure $1 D$ during constant-frequency trains. ${ }^{* * *} p<0.001$.
To test this hypothesis, we used an AP-clamp approach to measure calcium influx during high-frequency spike trains in presynaptic CA3 neurons. In AP clamp, the voltage-gated calcium channels (VGCCs) experience the same trajectory of voltage changes as during the AP trains, and thus calcium influx occurs with the time course and amplitude that closely approximate what occurs during high-frequency neuronal firing (Bean, 2007). N-type and P/Q-type calcium channels, the two predominant VGCCs in presynaptic terminals of CA3 neurons (Wheeler et al., 1994; Wu and Saggau, 1994; Elliott et al., 1995), jointly carry the bulk of presynaptic calcium transients that trigger neurotransmitter release (Dunlap et al., 1995). Previous studies revealed highly differential spatial distribution of different types of VGCCs in CA3 pyramidal cells and other central neurons: N-type and P/Q-type channels were found to be localized predominantly at the nerve terminals with substantially lower density at the soma, whereas the L-type channels are expressed almost exclusively in the soma and proximal dendrites but not at the synaptic terminals (Westenbroek et al., 1992, 1995; Elliott et al., 1995). Because of this highly specialized spatial distribution of VGCCs and inaccessibility of presynaptic terminals to patch-clamp recording in most central neurons, somatic recordings in combination with pharmacology have been widely used to infer about the properties of presynaptic calcium currents (Luebke et al., 1993; Wheeler et al., 1994; Dunlap et al., 1995; Evans and Zamponi, 2006).

We thus recorded APs evoked in CA3 PCs by a $60 \mathrm{~Hz}$ train through current injections in the whole-cell recording configuration and then used these AP trains as voltage commands for the same (corresponding genotype) neurons. The total calcium current was isolated first using the calcium channel blocker $\mathrm{Cd}^{2+}$ in the presence of TEA (20 mM), 4-AP (3 mM), and TTX $(1 \mu \mathrm{M})$ (Fig. $6 A)$. The peak of total calcium current $\left(I_{\mathrm{Ca}}\right)$ had a transient increase at the very beginning of the train that was similar in both groups (WT, $1.53 \pm 0.24 \mathrm{nA} ; \mathrm{KO}, 1.59 \pm 0.08 \mathrm{nA} ; p>$ $0.05 ; n=6$ for each) (data not shown), followed by a decline in amplitude during the train. This decline, however, was significantly smaller in the KO mice (average $I_{\mathrm{Ca}}$ for the last 10 stimuli in the train: WT, $74.2 \pm 0.5 \%$ of control; KO, $82.7 \pm 0.6 \%$ of control; $p<0.001 ; n=6$ for each group) (data not shown). Most importantly, the calcium charge transfer (i.e., calcium influx), calculated as a time inte- 
gral of the calcium transient, was markedly larger in the $\mathrm{KO}$ mice relative to WT mice during the train (Fig. 6B) (WT, $74.5 \pm 0.9 \%$ of control; KO, $107 \pm 1.2 \%$ of control, measured as the average for the last 10 spikes of the train; $p<0.001 ; n=6$ for each group), without significant difference for the first two APs. As a result, the cumulative calcium influx was significantly larger in the Fmr1 KO mice during the trains, except for the first few stimuli (Fig. 6C).

To more specifically examine changes in calcium influx through $\mathrm{N}$ - and $\mathrm{P} / \mathrm{Q}-$ type VGCCs, we performed the above experiments with the L-type calcium channel blocker nimodipine $(10 \mu \mathrm{M})$ added to the external solution. In addition, the above AP-clamp experiments were performed using $\mathrm{K}^{+}$-based pipette solution to first record AP trains from CA3 pyramidal neurons and then use those AP trains as voltage commands applied to the same neurons. The presence of high $\mathrm{K}^{+}$concentration in the pipette might influence the accuracy of measuring calcium currents. We thus measured calcium currents from CA3 pyramidal cells using the previously recorded AP trains as voltage commands and a $\mathrm{Cs}^{+}$based pipette solution containing TEA (20 mM), as well as the external solution containing nimodipine $(10 \mu \mathrm{M})$, TEA (20 $\mathrm{mM})$, 4-AP (3 mM), and TTX (1 $\mu \mathrm{M})$. Under these conditions, $\mathrm{N}$ - and P/Q-type currents represent $\sim 50 \%$ of the total calcium current, similar to previous reports (Elliott et al., 1995). With the L-type currents blocked, we also observed significantly larger $\mathrm{Ca}^{2+}$ charge transfer during high-frequency trains in Fmrl KO mice relative to WT controls (Fig. 6D,E) (WT, $61.0 \pm 1.3 \%$ of control, $n=8 ; \mathrm{KO}, 85.3 \pm$ $2.1 \%$ of control, $n=11$; measured as the average for the last 10 spikes of the train; $p<0.001)$. These results show that hippocampal CA3 neurons in Fmr1 KO mice exhibit enhanced calcium influx through N-type and P/Q-type VGCCs during highfrequency stimulus trains longer than a few stimuli. Because $\mathrm{N}$-type and P/Q-type VGCCs mediate the bulk of synaptic transmission in CA3 neurons, if the above phenomenon is also present in presynaptic terminals, it could explain the observed increase in augmentation, but not in facilitation, measured with the paired-pulse protocol (Figs. 4, 5).
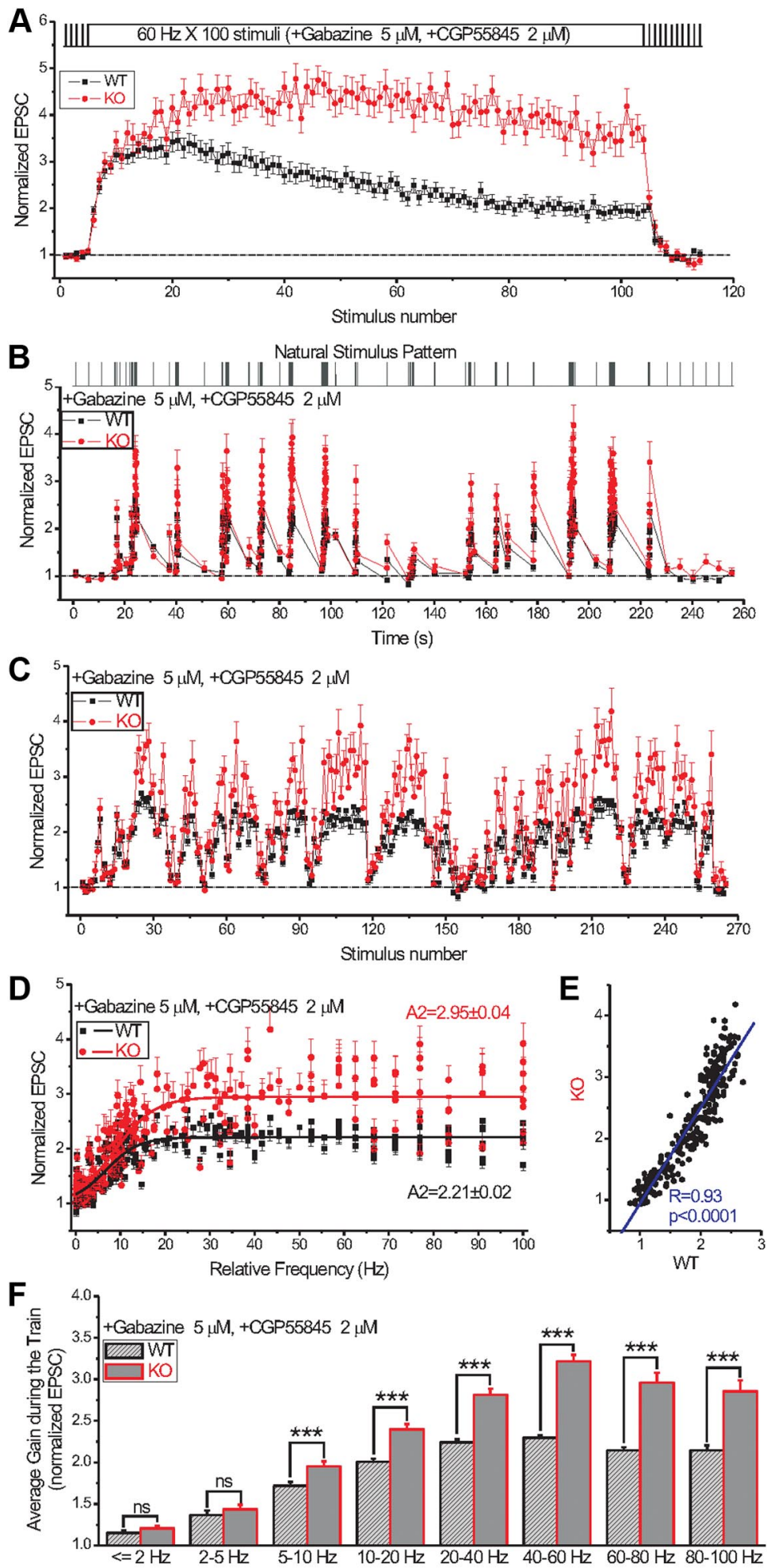

Figure 3. Enhanced excitatory responses to high-frequency stimulation in $F m r 1 \mathrm{KO}$ mice are not attributed to changes in inhibitory

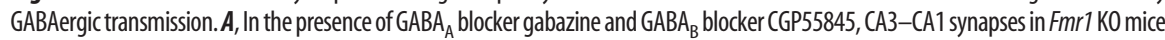
still exhibited enhanced responses to $60 \mathrm{~Hz}$ train stimulation similar to that observed with inhibition intact. $n=7$ for WT and $n=9$ for KO . $\boldsymbol{B}-\boldsymbol{F}$, In the presence of $\mathrm{GABA}_{\mathrm{A}}$ and $\mathrm{GABA}_{B}$ blockers, $\mathrm{CA} 3-\mathrm{CA} 1$ excitatory synapses in $F m r 1 \mathrm{KO}$ mice exhibited the same abnormally enhanced responses to natural stimulus trains as when GABA blockers were absent (see Fig. 2). $n=7$ for WT and $n=11$ for K0. Panels are aligned as in Figure $2 .{ }^{* * *} p<0.001$.
Reduced short-term depression in Fmr1 KO mice

In addition to increased augmentation, the excessive enhancement observed in Fmr1 KO mice during high-frequency stimulation can arise in part from reduced short-term depression. We thus examined the recovery from depression using single test pulses applied at different intervals after a high-frequency train (60 Hz, 150 stimuli) (Fig. 7A). Because recovery from depression overlaps with the decay of augmentation, the actual measured 

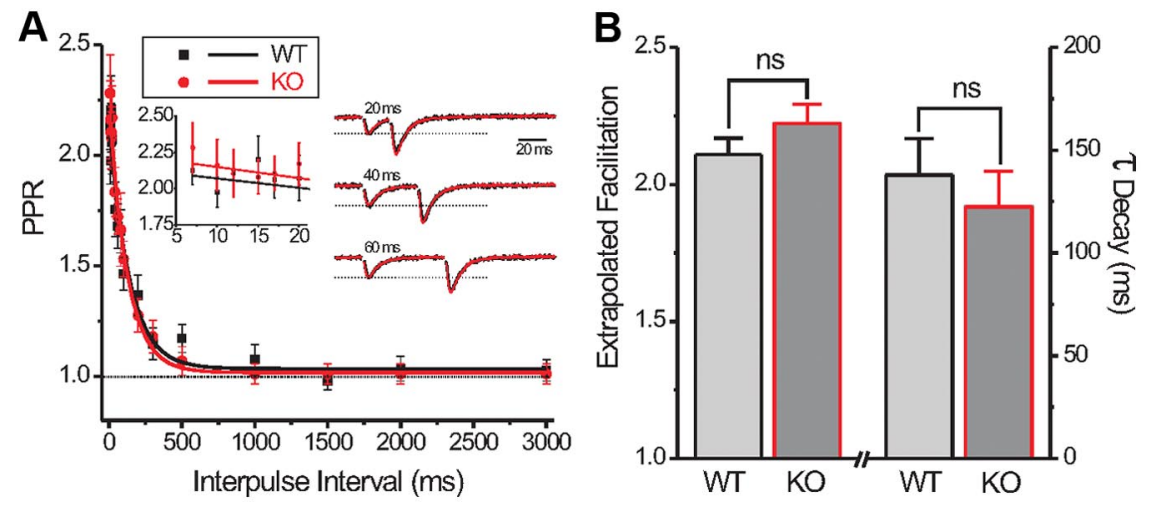

Figure 4. Facilitation is not altered in hippocampal synapses of $F m r 1 \mathrm{~K} 0$ mice. $\boldsymbol{A}, \boldsymbol{B}, \mathrm{PPR}$ was measured at intervals from 7 to $3000 \mathrm{~ms}$ in Fmr1 $\mathrm{KO}$ mice and WT controls. Monoexponential fits to the data were used to determine the amplitude of facilitation and the decay time constant; both were not significantly different between WT and K0 animals. $n=9$ for WT; $n=15$ for KO. $A$, Left inset shows PPR values measured at very short ISIs (7-20 ms) on an expanded timescale. Inset on the right shows examples of paired-pulse traces at 20,40, and 60 ms intervals, scaled to the first EPSC in the pair for each interval.
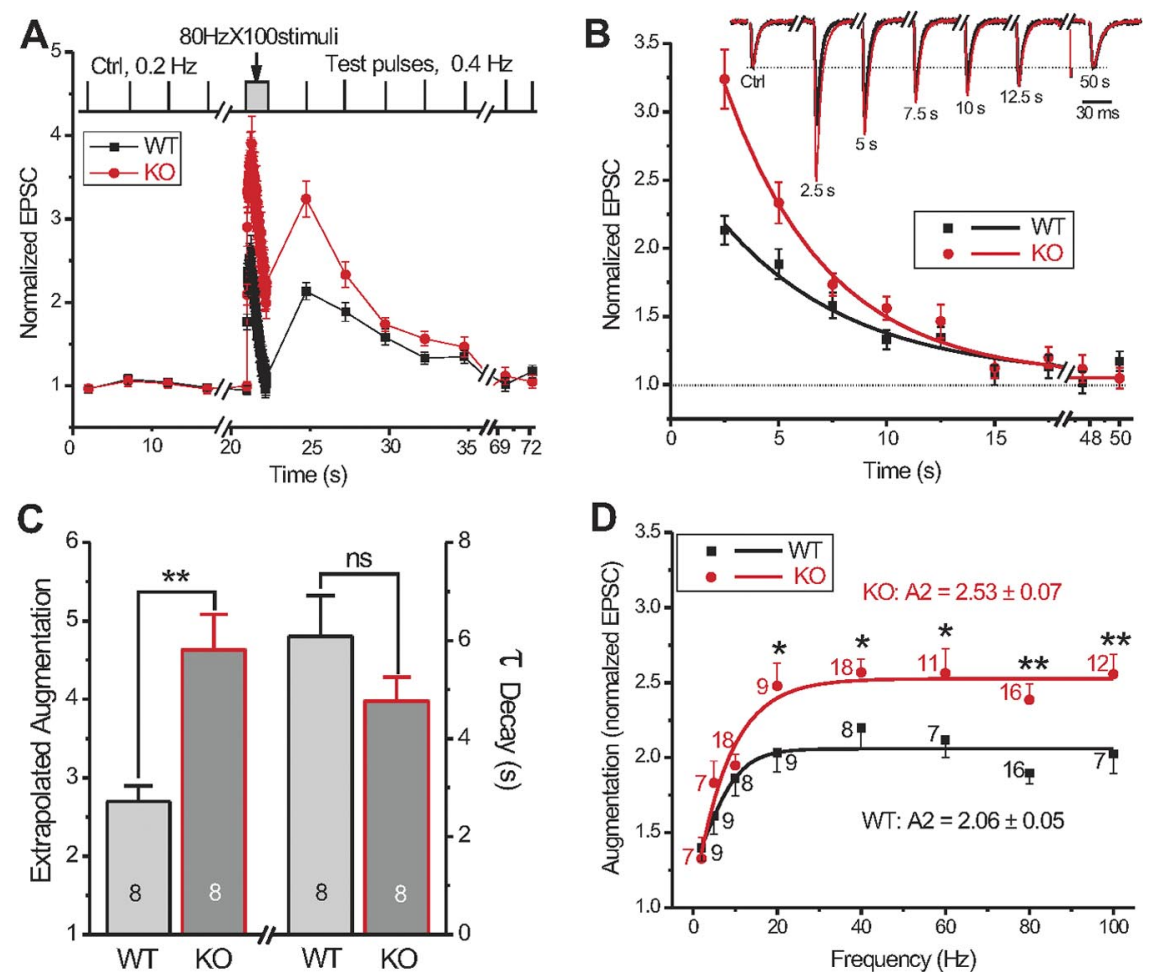

Figure 5. Augmentation is enhanced in excitatory synapses of Fmr1 $\mathrm{KO}$ mice. $\boldsymbol{A}-\boldsymbol{C}$, Augmentation was examined using single test pulses at 2.5 s intervals after 100 stimuli at $80 \mathrm{~Hz}(\boldsymbol{A})$. Parameters of augmentation were extracted using monoexponential fits to normalized EPSC decay as described previously (Klyachko and Stevens, 2006a) (B, C). Inset in $\boldsymbol{B}$ shows EPSCs recorded in response to test stimuli at indicated time points, revealing significantly enhanced augmentation in KO mice relative to WT mice. The time course of augmentation decay was not significantly altered in $\mathrm{KO}$ mice $(p=0.32)(\boldsymbol{C}), n=8$ for each. $\boldsymbol{D}$, Augmentation amplitude was measured $5 \mathrm{~s}$ after the end of 100 stimuli at 2-100 Hz. Data were fitted by Boltzmann equation, as shown by the solid lines. Augmentation was significantly enhanced in $\mathrm{Fmr} 1 \mathrm{KO}$ mice at stimulus frequencies $\geq 20 \mathrm{~Hz}$. Number of neurons tested is shown for each frequency. Data at $80 \mathrm{~Hz}$ combines two sets of recordings using either 2.5 or $5 \mathrm{~s}$ test pulse intervals pooled together. ${ }^{*} p<$ $0.05,{ }^{* *} p<0.01$.

EPSC amplitude reflects the net effect of these two components rather than depression alone. To isolate depression, we corrected synaptic responses for contributions from augmentation as we described previously (see figure legend and Klyachko and Stevens, 2006a). This analysis revealed a significant decrease in the amplitude of synaptic depression in Fmr1 KO mice (Fig. 7 B, C) (extrapolated depression amplitude was $0.83 \pm 0.04$ in WT vs
$0.68 \pm 0.02$ in $\mathrm{KO} ; p<0.01$ ), without significant changes in the recovery time constant (Fig. 7C). These data suggest that loss of FMRP causes abnormally potentiated synaptic responses during stimulus trains in part by reducing short-term depression.

\section{Facilitated kinetics of vesicle turnover in Fmr1 KO mice}

What is the mechanism of reduced shortterm depression in Fmr1 KO mice? In hippocampal synapses, vesicle depletion is believed to be the dominant contributor to short-term depression (Zucker and Regehr, 2002). A number of postsynaptic processes, such as receptor desensitization and saturation, have also been shown to contribute to short-term depression in some experimental systems (Chen et al., 2002; Wong et al., 2003), but these mechanisms have been found not to play a significant role in hippocampal STP (Wesseling and Lo, 2002; Klyachko and Stevens, 2006a). Reduced vesicle depletion and synaptic depression in Fmrl $\mathrm{KO}$ may thus arise in part from changes in vesicle recycling or in the number of vesicles available for release. We examined the first possibility using an imaging approach to study the kinetics of vesicle turnover in individual synaptic terminals of cultured hippocampal neurons (Fig. 8A), following protocols developed previously (Ryan and Smith, 1995). Synaptic vesicles were labeled with the fluorescent lipophilic marker FM1-43 [N-(3-triethylammoniumpropyl)4-(4-(dibutylamino)styryl) pyridinium dibromide] $(10 \mu \mathrm{M})$ via compensatory endocytosis using a $10 \mathrm{~Hz}, 100$-stimuli train; vesicle release was subsequently evoked by $1000 \mathrm{APs}$ at $10 \mathrm{~Hz}$, shown previously to release all recycling vesicles (Ryan and Smith, 1995). These imaging experiments were performed at $37^{\circ} \mathrm{C}$. Note that our loading protocol is expected to label the majority of recycling vesicles, based on previous estimates at room temperature ( $\sim 40 \%$ of total recycling pool) (Ryan and Smith, 1995) and taking into account that facilitation and particularly augmentation (and thus release probability during the stimulus train) are increased several-fold at body temperature, at which our recordings were performed (Klyachko and Stevens, 2006a). Using this approach, we found that the kinetics of FM1-43 destaining is accelerated significantly in Fmr1 KO relative to WT mice (Fig. 8 B) (WT, $19.3 \pm 1.4$ s; KO, $12.3 \pm 0.8 \mathrm{~s} ; n=320 \mathrm{WT}$ and $455 \mathrm{KO}$ synapses from 10 and 15 animals, respectively; $p<$ 0.01 ). Because the dye unloading under these conditions has been shown previously to reflect the kinetics of vesicle turnover (Ryan and Smith, 1995), these data suggest that loss of FMRP accelerates vesicle recycling. Faster vesicle recycling in Fmr1 KO is indeed likely to lead 
to reduced vesicle depletion and short-term depression (Zucker and Regehr, 2002).

Enlarged vesicle pools in Fmr1 $\mathrm{KO}$ mice In addition to faster vesicle recycling, reduced short-term depression in Fmrl KO mice can also arise, in part, from changes in the size of vesicle pools (Zucker and Regehr, 2002). To measure the morphological vesicle pool size directly, we performed ultrastructural analysis of CA1 excitatory synapses of 4- to 5-week-old Fmr1 KO and WT mice using electron microscopy (Fig. 9A). We found a significant increase in the number of both docked and undocked vesicles in EM micrographs of Fmrl KO mice (Fig. 9B) (docked vesicles: WT, $13.8 \pm 0.4 ; \mathrm{KO}, 15.6 \pm 0.5, p<$ 0.01 ; undocked vesicles: WT, $67.7 \pm 3.4$; $\mathrm{KO}, 87.0 \pm 4.3, p<0.001 ; n=132$ synapses from 3 WT mice and $n=148$ synapses from $4 \mathrm{KO}$ mice). No significant differences in synaptic density and active zone length were found between the two groups (Fig. 9C). The number of docked vesicles has been shown to strongly correlate with the size of the functionally defined readily-releasable vesicle pool (RRP) (Rosenmund and Stevens, 1996; Schikorski and Stevens, 2001), whereas the number of undocked vesicles represents mostly the reserved vesicle pool. Together, these data suggest that loss of FMRP leads to an increase in the size of both the RRP and the reserved vesicle pool, which may contribute to reduced depletion in Fmr1 KO mice.

Our morphological findings of an increased RRP size are supported by the functional estimates of the RRP size that we obtained using analysis of cumulative release during steady-state depression (Schneggenburger et al., 1999). This approach is based on the assumption that, under conditions of steady-state depression during prolonged high-frequency trains, the transmission is limited mostly by a resupply of vesicles. In this case, the linear back-extrapolation of the steadystate release levels during prolonged highfrequency activity has been shown to be proportional to the product of the RRP size $(n)$ and the quantal size $(q)$ (Schneggenburger et al., 1999). Our analysis of cumulative release during high-frequency trains using this approach indicates a significantly increased $n^{*} q$ value in Fmr1 KO mice during steadystate depression (WT, 76.8 $\pm 5.2, n=50 ; \mathrm{KO}, 132.2 \pm 6.7, n=82$; $p<0.0001$ ) (Fig. 9D,F). To determine whether this increase arises mostly from the changes in the RRP size or in the quantal size, we estimated the quantal size $q$ by recording the spontaneous miniature EPSCs (mEPSCs) from CA1 pyramidal cells (Fig. 9E). Both amplitude and frequency of mEPSCs were not significantly altered in the Fmr1 KO mice [amplitude: WT, $26.4 \pm 2.0 \mathrm{pA}$; KO,
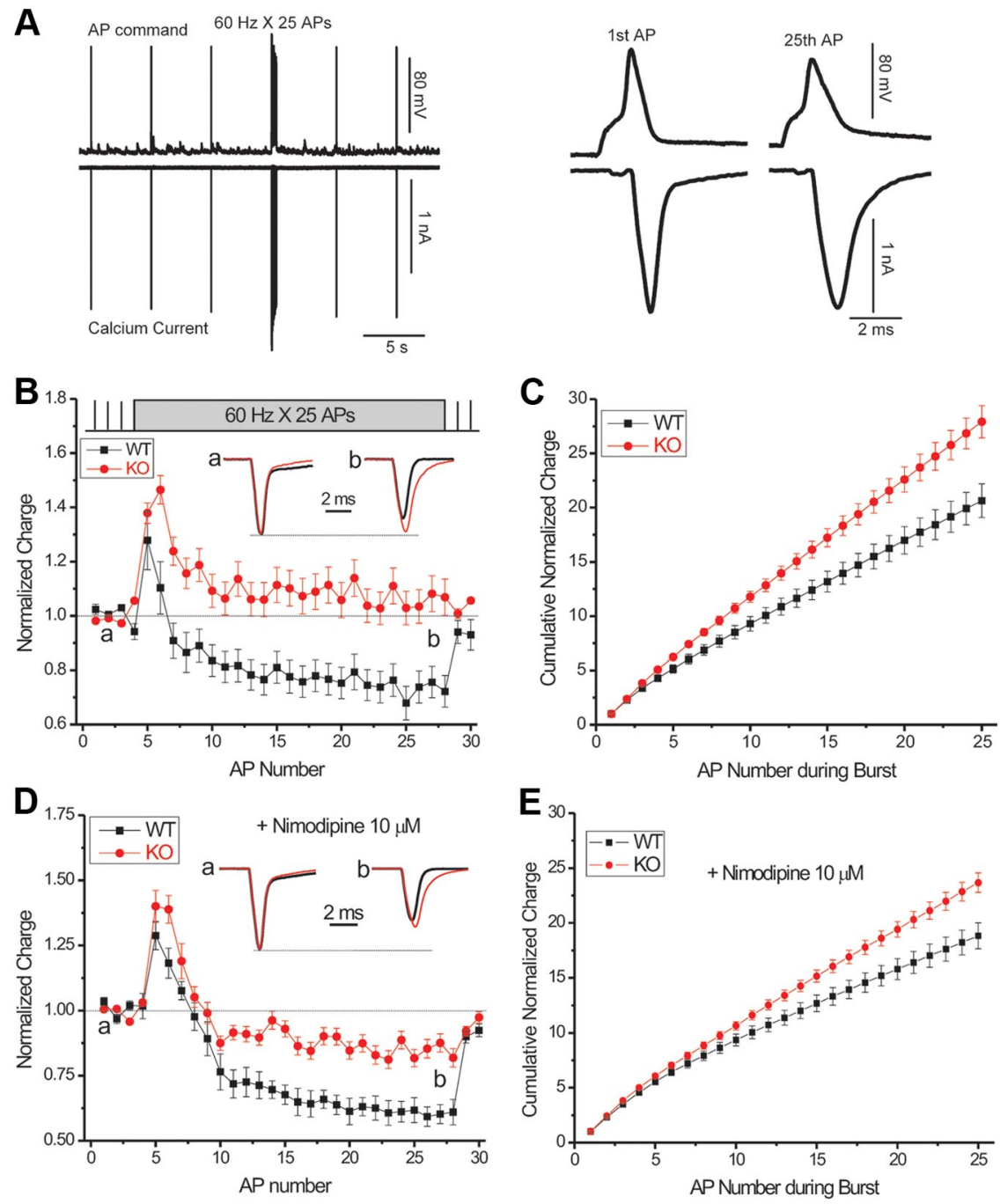

Figure 6. Calcium influx is enhanced during high-frequency stimulation in Fmr1 KO mice. A, Example of an AP-clamp experiment in Fmr $1 \mathrm{KO}$ CA3 pyramidal cell. A $60 \mathrm{~Hz}, 25-\mathrm{AP}$ train was evoked by injecting brief positive current pulses into $\mathrm{CA} 3$ pyramidal cell with a resting potential of $-60 \mathrm{mV}$. The recorded AP train was then used as the voltage command for the same cell to evoke calcium currents. Calcium currents were isolated using digital subtraction of traces recorded before and after $\mathrm{Cd}^{2+}$ application in the presence of TTX, TEA, and 4-AP. The entire train of APs (top trace) and the corresponding evoked calcium currents (bottom trace) are shown on the left; the first and 25th AP during the train and corresponding $\mathrm{Ca}^{2+}$ currents are shown on an expanded timescale on the right. Note the broadening of APs and $\mathrm{Ca}^{2+}$ current during the train. $\mathrm{B}, \mathrm{Ca}^{2+}$ charge transfer $\left(\mathrm{Ca}^{2+}\right.$ influx) during the AP train is plotted versus AP number in the train. Charge transfer was calculated as an integral of AP-evoked calcium transients. Insets show $\mathrm{Ca}^{2+}$ current traces for the denoted points, which were normalized and scaled to their own control $(\boldsymbol{a})$. Calcium current broadened to a larger extent in $F m r 7 \mathrm{KO}$ mice at the $\boldsymbol{b}$ point, leading to the greater $\mathrm{Ca}^{2+}$ influx in the $\mathrm{KO}$ neurons than that of WT. $n=6$ each for WT and KO mice. C, Cumulative $\mathrm{Ca}^{2+}$ charge transfer plotted versus AP number during the 25-AP burst, indicating larger intracellular $\mathrm{Ca}^{2+}$ buildup in $F m r 1 \mathrm{KO}$ mice during the AP trains after the first few stimuli. D, E. Same as ( $\boldsymbol{B}$, C) for the $\mathrm{Ca}^{2+}$ influx and cumulative calcium influx through non-L-type voltage-gated $\mathrm{Ca}^{2+}$ channels. Recordings were performed using $\mathrm{Cs}^{+}$-based pipette solution. Nimodipine $(10 \mu \mathrm{m})$ was added to the bath to block L-type $\mathrm{Ca}^{2+}$ channels. As in $\boldsymbol{B}$ and C, greater $\mathrm{Ca}^{2+}$ influx was found through non-L-type voltage-gated $\mathrm{Ca}^{2+}$ channels during high-frequency stimulation. $n=9$ for WT and $n=11$ for K0 animals.

$24.0 \pm 1.6 \mathrm{pA} ; n=6$ for each, $p=0.36$ (Fig. $9 F$ ); frequency: WT, $0.65 \pm 0.13 \mathrm{~Hz} ; \mathrm{KO}, 0.48 \pm 0.18 \mathrm{~Hz} ; n=6$ for each, $p=0.42($ data not shown)]. Therefore, the quantal size $q$ is not significantly altered by FMRP loss at CA3-CA1 synapses, in agreement with previous studies (Braun and Segal, 2000; Pfeiffer and Huber, 2007), thus confirming our morphological findings of increased RRP size attributable to FMRP loss.

\section{Discussion}

Our results demonstrate that excitatory CA3-CA1 hippocampal synapses in Fmrl KO mice exhibit abnormal presynaptic STP and 
A

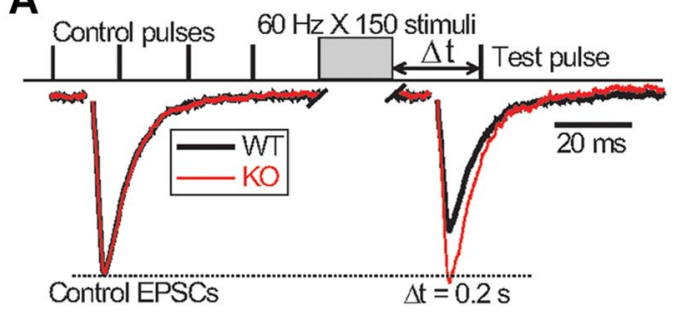

B
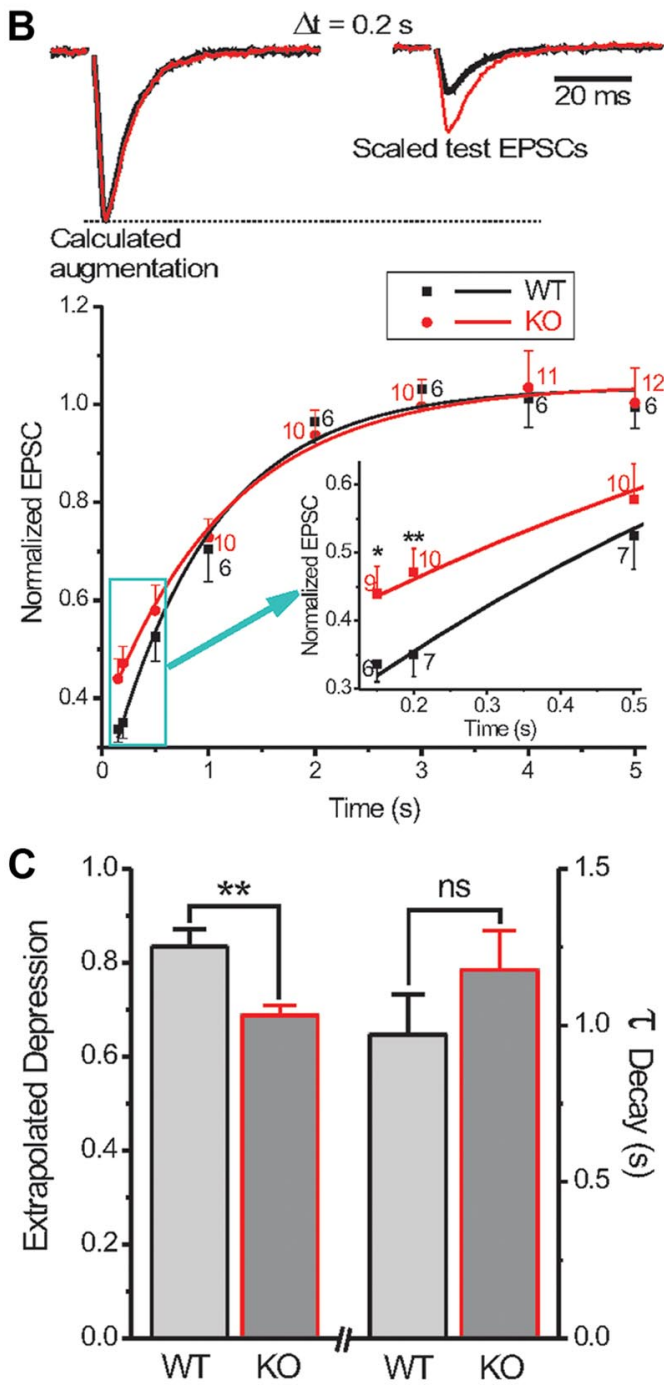

Figure 7. Short-term depression is reduced in $F m r 1 \mathrm{~K} 0$ mice. $A$, Recovery from depression was examined using single test pulses at variable intervals $(0.15-5 \mathrm{~s})$ after 150 stimulus trains at $60 \mathrm{~Hz}$ as described previously (Klyachko and Stevens, 2006a). Traces show an example of EPSCs recorded $0.2 \mathrm{~s}$ after the end of the stimulus trains in WT and KO mice. EPSCs were scaled to their own controls and showed larger extent of recovery in the KO animals than in WT animals. $\boldsymbol{B}$, To correct recovery from depression for overlapping decay of augmentation, the latter was also examined in the same recordings using test pulses at $5 \mathrm{~s}$ intervals after the depression-inducing train (i.e., 150 stimuli at $60 \mathrm{~Hz}$ ). Augmentation parameters were determined from monoexponential fits to the data as described previously (Fig. 5) and extrapolated to the earlier time points $(0.15-5 \mathrm{~s})$ used to estimate depression. At each time point, the depression then was corrected by scaling the measured EPSCs by the calculated augmentation at the same time points (Klyachko and Stevens, 2006b). The top shows an example of calculated augmentation EPSCS (reconstructed from EPSC template) at 0.2 s after the depression-inducing train and the scaled test EPSCs at the same time point. For presentation only the calculated augmentation EPSCS of WT and KO mice were normalized to the same level for comparison. This analysis revealed the true extent of depression as shown in the bottom for each time point. Depression amplitude and recovery time constant were determined from monoexponential fits shown by the solid lines. The number of cells tested is shown for each time point. Inset shows altered information processing. We observed strongly enhanced augmentation and reduced short-term depression attributable to loss of FMRP. These changes were associated with heightened $\mathrm{Ca}^{2+}$ influx in presynaptic CA3 neurons during high-frequency spike trains, faster synaptic vesicle recycling, and increased vesicle pools. As a result, hippocampal synapses in Fmr1 KO mice exhibited abnormal processing of natural stimulus patterns, specifically hypersensitivity to high-frequency bursts associated with hippocampal place fields. Our results thus demonstrate major functional and morphological presynaptic defects leading to abnormal STP in the absence of FMRP. Given the important roles of STP in information processing, working memory, and decision making (Fioravante and Regehr, 2011), the observed STP dysfunction may contribute to cognitive deficits in FXS.

\section{Abnormal STP in Fmr1 KO mice}

STP represents a rapid, use-dependent modulation of synaptic strength and comprises several dynamic processes-namely facilitation, augmentation, and depression - that have a predominantly presynaptic origin in most small central synapses (Zucker and Regehr, 2002). We found that augmentation, but not facilitation, is significantly increased in excitatory hippocampal synapses in Fmrl KO mice, whereas short-term depression is decreased. These STP defects in Fmr1 KO mice have been mostly overlooked previously because the majority of studies of presynaptic function rely on so-called PPR measurements as a sole indicator of presynaptic changes. In agreement with the previous studies (Pfeiffer and Huber, 2007; Zhang et al., 2009), we did not observe significant changes in PPR in hippocampal synapses (Fig. 4). Augmentation, however, represents a longer-lasting form of short-term enhancement than facilitation and requires more extensive stimulation to be evoked in detectable quantities. The excessive frequency-dependent increase in augmentation in Fmr1 KO mice (Fig. 5D) closely parallels that of the overall increase in synaptic strength during high-frequency trains (Figs. $1 D, 2 C)$. This result suggests that increased augmentation may serve as the dominant mechanism of abnormal STP in Fmrl KO animals. Interestingly, the only previous study that directly examined effects of FMRP loss on augmentation using Drosophila neuromuscular junction (NMJ) did not find significant changes (Repicky and Broadie, 2009). These apparent discrepancies may result from the stimulus frequencies used, mostly outside of the high-frequency range within which we detected significant changes in augmentation. In addition, augmentation appears to have, at least in part, different mechanisms in the NMJ and the hippocampal synapses (Magleby and Zengel, 1982; Kandaswamy et al., 2010).

In addition to enhanced augmentation, we observed reduced short-term depression in Fmr1 KO mice (Fig. 7). In hippocampal synapses, short-term depression is thought to be driven mostly by the depletion of the readily-releasable vesicles (Zucker and Regehr, 2002). Our findings of faster vesicle recycling concomitant with increased vesicle pools at CA3-CA1 synapses (Figs. 8, 9) thus provide likely mechanisms for reduced short-term depression in Fmr1 KO mice. An elevated rate of vesicle cycling attributable to loss of FMRP has also been described previously in the Drosophila

$\leftarrow$

the earlier time points on expanded timescale. ${ }^{*} p<0.05,{ }^{* *} p<0.01$. C, Depression amplitude extrapolated to $t=0$ (revealing extent of depression at the end of the highfrequency train) was significantly reduced in $\mathrm{K} 0$ mice, without change in the recovery time constant. ${ }^{* *} p<0.01$ 
NMJ (Gatto and Broadie, 2008), but whether changes in vesicle pool sizes occurred has not been reported. It remains to be determined whether increased vesicle pools is a secondary effect resulting from faster vesicle recycling or whether these presynaptic changes arise from independent mechanisms.

Mechanisms of STP dysfunction in FXS What are the mechanisms of these presynaptic changes associated with the loss of FMRP? Elevation in residual presynaptic $\mathrm{Ca}^{2+}$ levels that drive augmentation during repetitive activity is determined by a combination of several processes, namely AP-driven $\mathrm{Ca}^{2+}$ influx, cytoplasmic $\mathrm{Ca}^{2+}$ buffering, uptake/release by internal stores, and calcium extrusion (Scott, 2007). Because we did not observe significant changes in the kinetics of augmentation decay, which is widely believed to reflect calcium clearance/sequestration processes (Zucker and Regehr, 2002), these processes may not be strongly affected by FMRP loss. Moreover, at the CA3-CA1 synapse, the $\mathrm{Ca}^{2+}$ release/uptake by internal stores have been shown not to play significant roles in STP on the timescales relevant to the current study (Carter et al., 2002). Calcium influx through VGCCs thus represents the major process driving buildup of residual calcium on these timescales in CA3-CA1 synapses (Dunlap et al., 1995). Our data show that $\mathrm{Ca}^{2+}$ influx during highfrequency stimulation is significantly increased in CA3 neurons as a result of loss of FMRP after the first few stimuli in the train (Fig. 6). This result is consistent with the observed increase in augmentation but not paired-pulse facilitation in Fmr1 $\mathrm{KO}$ animals (Figs. 4, 5).

One possible mechanism of the enhanced $\mathrm{Ca}^{2+}$ influx is the increase in calcium channel open time caused by prolongation of APs in Fmr1 KO animals. This possibility is supported by the evidence that expression of the voltage-gated potassium channels Kv3.1b (Strumbos et al., 2010) and Kv4.2 (Gross et al., 2011) is positively regulated by FMRP in the brainstem and hippocampal neurons, respectively. Decreased number of voltagegated $\mathrm{K}^{+}$channels in the absence of FMRP could cause excessive AP broadening, in turn leading to increased presynaptic $\mathrm{Ca}^{2+}$ influx. Another potential mechanism of elevated calcium influx is direct modulation of VGCC properties by FMRP. A recent study reported that FMRP can directly interact with and modulate gating of at least one type of ion channel, the sodium-activated $\mathrm{K}^{+}$channel Slack (Brown et al., 2010). It remains to be determined whether FMRP also modulates the activity of other

A animals.
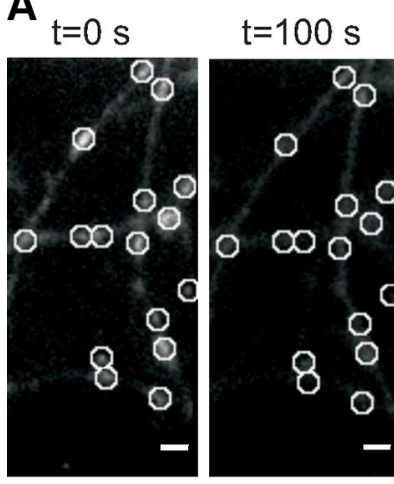

B

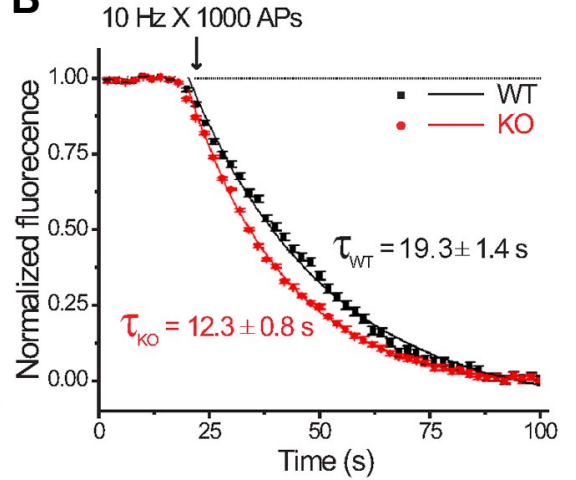

Figure 8. Vesicle pool turnover is faster in Fmr1 KO mice. $\boldsymbol{A}$, Hippocampal synapses in culture (days 14-18) were labeled with FM1-43 $(10 \mu \mathrm{M})$ presented during and for $90 \mathrm{~s}$ after a 100 stimulus train at $10 \mathrm{~Hz}(t=0)$. After a washing period, the dye was released with 1000 stimuli at $10 \mathrm{~Hz}(t=100 \mathrm{~s}$ ). An example of dye loading and unloading in WT neurons is shown. Scale bar, $2 \mu \mathrm{m}$. $\boldsymbol{B}$, Averaged dye release kinetics in WT and $F m r 1 \mathrm{KO}$ mice at $37^{\circ} \mathrm{C}$. Note the faster destaining kinetics in KO synapses $(n=320 \mathrm{WT}$ and $455 \mathrm{KO}$ synapses from 10 and 15 animals, respectively; $p<0.01$ ).
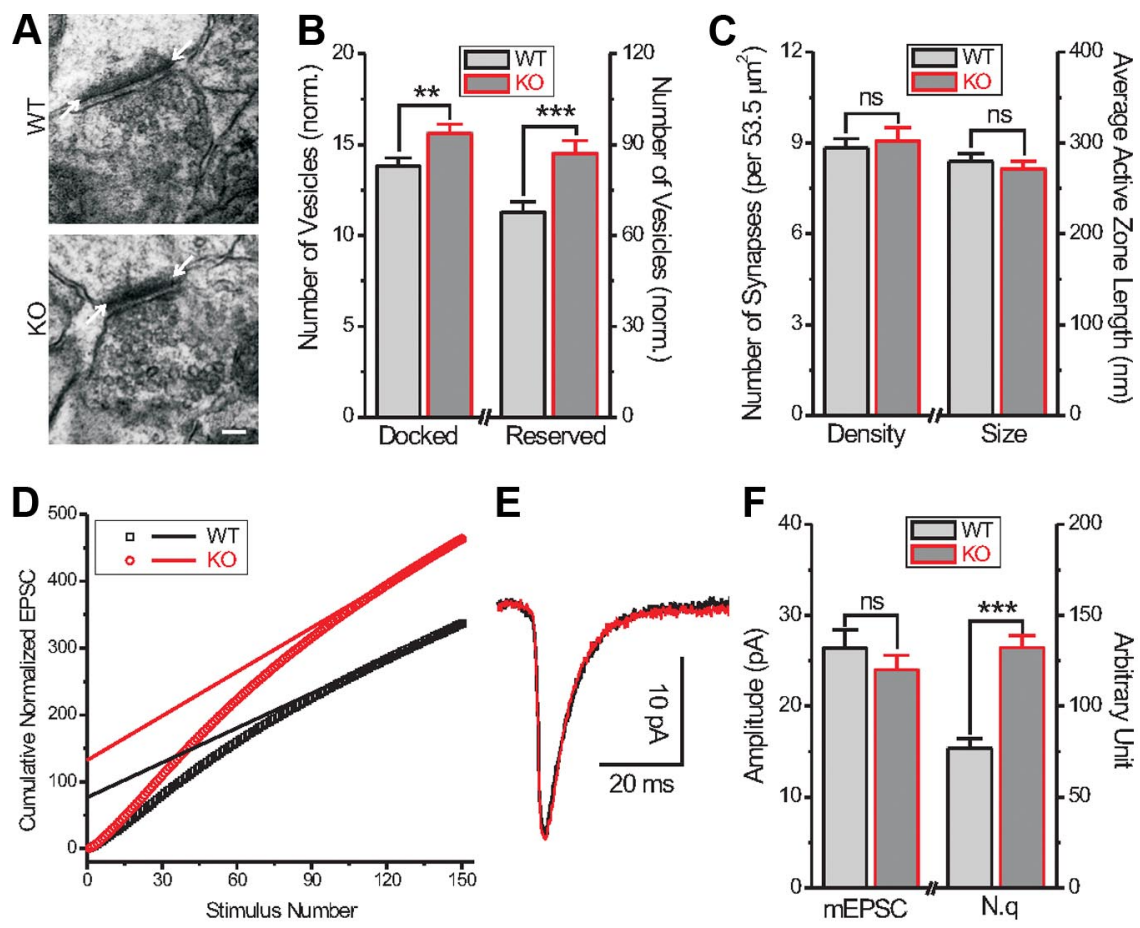

Figure 9. Vesicle pools are enlarged in excitatory hippocampal synapses of Fmr $1 \mathrm{KO}$ mice. $\boldsymbol{A}$, Transmission electron microscopy images of asymmetric excitatory synapses in the CA1 stratum radiatum. Arrows show the points used to measure the length of postsynaptic density. Scale bar, $100 \mathrm{~nm}$. B, Analysis of vesicle counts in excitatory CA3-CA1 synapses shows significant increases in the numbers of both docked and reserved vesicles in Fmr $1 \mathrm{KO}$ mice. Vesicle counts were normalized to the active zone size (vesicles per micrometer) as evaluated by the postsynaptic density length. ${ }^{* *} p<0.01$ or ${ }^{* * *} p<0.001 ; n=132$ synapses from 3 WT mice and $n=148$ synapses from 4 KO mice. C, No significant differences in the density of asymmetric synapses and length of postsynaptic density (as an estimate for the length of the active zone) were found. $\boldsymbol{D}$, Analysis of cumulative normalized EPSCs during 150 stimuli at $60 \mathrm{~Hz}$ was used to estimate changes in the functional RRP size. For each cell, the last 10 cumulative EPSC points were fitted with a linear regression line and extrapolated to the time $t=0$ to estimate the $N^{*} q$ value, as shown in $\boldsymbol{F} . n=50$ for WT, $n=82$ for KO. $\boldsymbol{E}$, The average mEPSC traces recorded in the presence of TTX in the WT and K0 animals. $\boldsymbol{F}$, The amplitude of mEPSC ( $n=6$ for each WT and K0; $p=0.36$ ) used to evaluate changes in quantal size $q$ and estimated $N^{*} q$ values ( $n=50$ for WT, $n=82$ for $\mathrm{KO}$; ${ }^{* * *} p<0.001$ ). No significant changes in $q$ were found, confirming that $N$, the functional RRP size, is increased in the Fmr $1 \mathrm{KO}$

types of ion channels, including presynaptic VGCCs. FMRP loss has also been shown to downregulate the expression of a major calcium buffer, calbindin D28K, in the hippocampal neurons (Real et al., 2011). Decreased levels of the presynaptic $\mathrm{Ca}^{2+}$ buffers have been shown to result in increased residual calcium levels in Drosophila 
mushroom body neurons (Tessier and Broadie, 2011) and may thus also contribute to heightened augmentation in hippocampal synapses.

Increased calcium levels are also known to facilitate vesicle recycling (Dittman and Regehr, 1998) and may thus represent a mechanism leading to reduced short-term depression in the absence of FMRP. Other potentially overlapping mechanisms may lead to reduced depression via increase in the size of vesicle pools in the Fmr1 KO mice (Fig. 9). Proteomics and translational profile analyses revealed that the levels of many presynaptic proteins involved in vesicle release and endocytosis/recycling are affected by loss of FMRP (Brown et al., 2001; Miyashiro et al., 2003; Liao et al., 2008). Changes in expression levels and/or activity of these proteins may lead to facilitated vesicle recycling and increased vesicle accumulation, thereby reducing synaptic depression in the absence of FMRP.

Alternative or concurrent with these potential presynaptic mechanisms of FMRP actions is trans-synaptic retrograde signaling arising from the postsynaptic site. The presence of a transsynaptic mechanism is suggested by evidence in the Drosophila model of FXS that constitutive presynaptic dFMRP expression could rescue presynaptic structural deficits in dFmrl null mutants but not the functional ones (Gatto and Broadie, 2008). Retrograde signaling mechanisms have indeed been shown to regulate quantal size and vesicle release in Drosophila NMJ synapses (Davis et al., 1998). Whether trans-synaptic mechanisms can alter calcium dynamics, vesicle recycling, or size of the vesicle pools remains to be determined. Given the variety of known FMRP functions at synapses, it is also conceivable that both cellautonomous and trans-synaptic mechanisms combine to determine presynaptic STP abnormalities arising from FMRP loss.

\section{Implications of STP dysfunction for information processing in FXS}

Our observation of abnormal STP in hippocampal synapses during physiologically relevant activity patterns may have important implications for cognitive dysfunctions in FXS individuals. Indeed, firing patterns of excitatory hippocampal neurons used here as a "natural" input to CA3-CA1 synapses were recorded from place cells of awake, freely moving rodents (Fenton and Muller, 1998), and their characteristics are typical of the input that hippocampal synapses may encounter in vivo. The function of place cells extends well beyond their well-described role in space representation. They have been shown to respond to various nonspatial sensory inputs and are generally believed to combine sensory information and spatial context to provide encoding of new context-specific or episodic information (Leutgeb et al., 2005). Abnormal synaptic information processing in the hippocampus may lead to dysfunctional learning abilities and thus contribute to cognitive deficits in FXS individuals. STP dysfunction in hippocampal synapses thus represents a first example of major presynaptic abnormalities leading to altered information processing in FXS.

Although they vary in relative abundance, the core mechanisms of STP are preserved in most central synapses (Zucker and Regehr, 2002). Our findings thus suggest the possibility that STP dysfunction is present in other brain regions, in which in addition to information processing, STP is thought to play important roles in working memory (Mongillo et al., 2008) and decision making (Deco et al., 2010). Moreover, spike bursts are a prominent feature of sensory coding in primary sensory and cortical neurons (Metzner et al., 1998; Leutgeb et al., 2005), and abnormal STP in these neurons, in combination with other factors, may explain hypersensitivity to sensory stimuli and hyperactivity observed in FXS individuals (Bassell and Warren, 2008). Future studies in other brain areas will establish the overall impact of STP abnormalities in cognitive impairments in FXS.

\section{References}

Abbott LF, Regehr WG (2004) Synaptic computation. Nature 431:796-803. Akins MR, Berk-Rauch HE, Fallon JR (2009) Presynaptic translation: stepping out of the postsynaptic shadow. Front Neural Circuits 3:17.

Bamji SX, Shimazu K, Kimes N, Huelsken J, Birchmeier W, Lu B, Reichardt LF (2003) Role of beta-catenin in synaptic vesicle localization and presynaptic assembly. Neuron 40:719-731.

Bassell GJ, Warren ST (2008) Fragile X syndrome: loss of local mRNA regulation alters synaptic development and function. Neuron 60:201-214.

Bean BP (2007) The action potential in mammalian central neurons. Nat Rev Neurosci 8:451-465.

Bear MF, Huber KM, Warren ST (2004) The mGluR theory of fragile X mental retardation. Trends Neurosci 27:370-377.

Braun K, Segal M (2000) FMRP involvement in formation of synapses among cultured hippocampal neurons. Cereb Cortex 10:1045-1052.

Brown MR, Kronengold J, Gazula VR, Chen Y, Strumbos JG, Sigworth FJ, Navaratnam D, Kaczmarek LK (2010) Fragile X mental retardation protein controls gating of the sodium-activated potassium channel Slack. Nat Neurosci 13:819-821.

Brown V, Jin P, Ceman S, Darnell JC, O'Donnell WT, Tenenbaum SA, Jin X, Feng Y, Wilkinson KD, Keene JD, Darnell RB, Warren ST (2001) Microarray identification of FMRP-associated brain mRNAs and altered mRNA translational profiles in fragile X syndrome. Cell 107:477-487.

Carter AG, Vogt KE, Foster KA, Regehr WG (2002) Assessing the role of calcium-induced calcium release in short-term presynaptic plasticity at excitatory central synapses. J Neurosci 22:21-28.

Centonze D, Rossi S, Mercaldo V, Napoli I, Ciotti MT, De Chiara V, Musella A, Prosperetti C, Calabresi P, Bernardi G, Bagni C (2008) Abnormal striatal GABA transmission in the mouse model for the fragile X syndrome. Biol Psychiatry 63:963-973.

Chen C, Blitz DM, Regehr WG (2002) Contributions of receptor desensitization and saturation to plasticity at the retinogeniculate synapse. Neuron 33:779-788.

Christie SB, Akins MR, Schwob JE, Fallon JR (2009) The FXG: a presynaptic fragile $\mathrm{X}$ granule expressed in a subset of developing brain circuits. J Neurosci 29:1514-1524.

Davis GW, DiAntonio A, Petersen SA, Goodman CS (1998) Postsynaptic PKA controls quantal size and reveals a retrograde signal that regulates presynaptic transmitter release in Drosophila. Neuron 20:305-315.

Deco G, Rolls ET, Romo R (2010) Synaptic dynamics and decision making. Proc Natl Acad Sci U S A 107:7545-7549.

Dickinson-Nelson A, Reese TS (1983) Structural changes during transmitter release at synapses in the frog sympathetic ganglion. J Neurosci 3:42-52.

Dittman JS, Regehr WG (1998) Calcium dependence and recovery kinetics of presynaptic depression at the climbing fiber to Purkinje cell synapse. J Neurosci 18:6147-6162.

Dunlap K, Luebke JI, Turner TJ (1995) Exocytotic $\mathrm{Ca}^{2+}$ channels in mammalian central neurons. Trends Neurosci 18:89-98.

Elliott EM, Malouf AT, Catterall WA (1995) Role of calcium channel subtypes in calcium transients in hippocampal CA3 neurons. J Neurosci 15:6433-6444.

Evans RM, Zamponi GW (2006) Presynaptic $\mathrm{Ca}^{2+}$ channels: integration centers for neuronal signaling pathways. Trends Neurosci 29:617-624.

Fenton AA, Muller RU (1998) Place cell discharge is extremely variable during individual passes of the rat through the firing field. Proc Natl Acad Sci U S A 95:3182-3187.

Fioravante D, Regehr WG (2011) Short-term forms of presynaptic plasticity. Curr Opin Neurobiol 21:269-274.

Gatto CL, Broadie K (2008) Temporal requirements of the fragile X mental retardation protein in the regulation of synaptic structure. Development 135:2637-2648.

Gibson JR, Bartley AF, Hays SA, Huber KM (2008) Imbalance of neocortical excitation and inhibition and altered UP states reflect network hyperexcitability in the mouse model of fragile X syndrome. J Neurophysiol 100:2615-2626.

Gross C, Yao X, Pong DL, Jeromin A, Bassell GJ (2011) Fragile x mental 
retardation protein regulates protein expression and mRNA translation of the potassium channel kv4.2. J Neurosci 31:5693-5698.

Hanson JE, Madison DV (2007) Presynaptic FMR1 genotype influences the degree of synaptic connectivity in a mosaic mouse model of fragile $\mathrm{X}$ syndrome. J Neurosci 27:4014-4018.

Huber KM, Gallagher SM, Warren ST, Bear MF (2002) Altered synaptic plasticity in a mouse model of fragile X mental retardation. Proc Natl Acad Sci U S A 99:7746-7750.

Kaech S, Banker G (2006) Culturing hippocampal neurons. Nat Protoc 1:2406-2415.

Kalkstein JM, Magleby KL (2004) Augmentation increases vesicular release probability in the presence of masking depression at the frog neuromuscular junction. J Neurosci 24:11391-11403.

Kandaswamy U, Deng PY, Stevens CF, Klyachko VA (2010) The role of presynaptic dynamics in processing of natural spike trains in hippocampal synapses. J Neurosci 30:15904-15914.

Klyachko VA, Stevens CF (2006a) Temperature-dependent shift of balance among the components of short-term plasticity in hippocampal synapses. J Neurosci 26:6945-6957.

Klyachko VA, Stevens CF (2006b) Excitatory and feed-forward inhibitory hippocampal synapses work synergistically as an adaptive filter of natural spike trains. PLoS Biol 4:e207.

Leutgeb S, Leutgeb JK, Moser MB, Moser EI (2005) Place cells, spatial maps and the population code for memory. Curr Opin Neurobiol 15:738-746.

Liao L, Park SK, Xu T, Vanderklish P, Yates JR 3rd (2008) Quantitative proteomic analysis of primary neurons reveals diverse changes in synaptic protein content in fmrl knockout mice. Proc Natl Acad Sci U S A 105:15281-15286.

Luebke JI, Dunlap K, Turner TJ (1993) Multiple calcium channel types control glutamatergic synaptic transmission in the hippocampus. Neuron 11:895-902.

Magleby KL, Zengel JE (1982) A quantitative description of stimulationinduced changes in transmitter release at the frog neuromuscular junction. J Gen Physiol 80:613-638.

Metzner W, Koch C, Wessel R, Gabbiani F (1998) Feature extraction by burstlike spike patterns in multiple sensory maps. J Neurosci 18:2283-2300.

Miyashiro KY, Beckel-Mitchener A, Purk TP, Becker KG, Barret T, Liu L, Carbonetto S, Weiler IJ, Greenough WT, Eberwine J (2003) RNA cargoes associating with FMRP reveal deficits in cellular functioning in Fmr1 null mice. Neuron 37:417-431.

Mongillo G, Barak O, Tsodyks M (2008) Synaptic theory of working memory. Science 319:1543-1546.

O'Keefe J, Dostrovsky J (1971) The hippocampus as a spatial map. Preliminary evidence from unit activity in the freely-moving rat. Brain Res 34:171-175.

Olmos-Serrano JL, Paluszkiewicz SM, Martin BS, Kaufmann WE, Corbin JG, Huntsman MM (2010) Defective GABAergic neurotransmission and pharmacological rescue of neuronal hyperexcitability in the amygdala in a mouse model of fragile X syndrome. J Neurosci 30:9929-9938.

Pfeiffer BE, Huber KM (2007) Fragile X mental retardation protein induces synapse loss through acute postsynaptic translational regulation. J Neurosci 27:3120-3130.

Pfeiffer BE, Huber KM (2009) The state of synapses in fragile X syndrome. Neuroscientist 15:549-567.

Pozzo-Miller LD, Gottschalk W, Zhang L, McDermott K, Du J, Gopalakrishnan R, Oho C, Sheng ZH, Lu B (1999) Impairments in high-frequency transmission, synaptic vesicle docking, and synaptic protein distribution in the hippocampus of BDNF knock-out mice. J Neurosci 19:4972-4983.
Real MA, Simon MP, Heredia R, de Diego Y, Guirado S (2011) Phenotypic changes in calbindin D28K immunoreactivity in the hippocampus of Fmr1 knockout mice. J Comp Neurol. Advance online publication. Retrieved June 22, 2011. doi:10.1002/cne.22643.

Repicky S, Broadie K (2009) Metabotropic glutamate receptor-mediated use-dependent down-regulation of synaptic excitability involves the fragile X mental retardation protein. J Neurophysiol 101:672-687.

Rosenmund C, Stevens CF (1996) Definition of the readily releasable pool of vesicles at hippocampal synapses. Neuron 16:1197-1207.

Ryan TA, Smith SJ (1995) Vesicle pool mobilization during action potential firing at hippocampal synapses. Neuron 14:983-989.

Schikorski T, Stevens CF (2001) Morphological correlates of functionally defined synaptic vesicle populations. Nat Neurosci 4:391-395.

Schneggenburger R, Meyer AC, Neher E (1999) Released fraction and total size of a pool of immediately availiable transmitter quanta at a calyx synapse. Neuron 23:399-409.

Scott R (2007) Use-dependent control of presynaptic calcium signalling at central synapses. J Anat 210:642-650.

Sternberg SR (1983) Biomedical image processing. Computer 16:22-34.

Strumbos JG, Brown MR, Kronengold J, Polley DB, Kaczmarek LK (2010) Fragile $\mathrm{X}$ mental retardation protein is required for rapid experience-dependent regulation of the potassium channel Kv3.1b. J Neurosci 30:10263-10271.

Tessier CR, Broadie K (2011) The fragile X mental retardation protein developmentally regulates the strength and fidelity of calcium signaling in Drosophila mushroom body neurons. Neurobiol Dis 41:147-159.

Thévenaz P, Ruttimann UE, Unser M (1998) A pyramid approach to subpixel registration based on intensity. IEEE Trans Image Process 7:27-41.

Wesseling JF, Lo DC (2002) Limit on the role of activity in controlling the release-ready supply of synaptic vesicles. J Neurosci 22:9708-9720.

Westenbroek RE, Hell JW, Warner C, Dubel SJ, Snutch TP, Catterall WA (1992) Biochemical properties and subcellular distribution of an N-type calcium channel a1 subunit. Neuron 9:1099-1115.

Westenbroek RE, Sakurai T, Elliott EM, Hell JW, Starr TV, Snutch TP, Catterall WA (1995) Immunochemical identification and subcellular distribution of the $\alpha$-1A subunits of brain calcium channels. J Neurosci 15:6403-6418.

Wheeler DB, Randall A, Tsien RW (1994) Roles of N-type and Q-type Ca ${ }^{2+}$ channels in supporting hippocampal synaptic transmission. Science 264:107-111.

Wong AY, Graham BP, Billups B, Forsythe ID (2003) Distinguishing between presynaptic and postsynaptic mechanisms of short-term depression during action potential trains. J Neurosci 23:4868-4877.

Wu LG, Saggau P (1994) Pharmacological identification of two types of presynaptic voltage-dependent calcium channels at CA3-CA1 synapses of the hippocampus. J Neurosci 14:5613-5622.

Zhang J, Hou L, Klann E, Nelson DL (2009) Altered hippocampal synaptic plasticity in the FMR1 gene family knockout mouse models. J Neurophysiol 101:2572-2580

Zhang L, Alger BE (2010) Enhanced endocannabinoid signaling elevates neuronal excitability in fragile X syndrome. J Neurosci 30:5724-5729.

Zhang YQ, Bailey AM, Matthies HJ, Renden RB, Smith MA, Speese SD, Rubin GM, Broadie K (2001) Drosophila fragile X-related gene regulates the MAP1B homolog Futsch to control synaptic structure and function. Cell 107:591-603.

Zucker RS, Regehr WG (2002) Short-term synaptic plasticity. Annu Rev Physiol 64:355-405. 